\title{
Contenido esencial del derecho-deber de cuidado personal de los hijos
}

\author{
Marcela Acuña San Martín*
}

\begin{abstract}
RESUMEN
A diferencia de lo que ocurre con otros derechos de la relación paterno-filial, el legislador no define qué es el cuidado personal de los hijos, ni lo dota de contenido. La ausencia de conceptualización legal conlleva que no se encuentre delimitado el ámbito de realidad protegido por el derecho. El trabajo delimita el contenido actual del derecho-deber de cuidado personal de los hijos a partir del análisis de elementos que conjugados aportan una concepción integral.
\end{abstract}

Cuidado personal de los hijos; custodia; corresponsabilidad parental

\section{Right-duty personal care of cbildren exential content}

\begin{abstract}
Unlike other rights of the paternal-filial relationship, legislator does not define what is personal care of children, nor does provide its content. The absence of legal conceptualization implies that the scope of reality protected by law is not delimited. The work delimits the current content of personal care of children right-duty, starting from the analysis of five elements that combine a comprehensive conception.
\end{abstract}

Personal care of children; custody; parental responsibility

* Licenciada en Ciencias Jurídicas y Sociales, Universidad Austral de Chile. Abogada. Doctora en Derecho, Universidad de Zaragoza, España. Profesora de Derecho, Universidad de Talca, Chile. Correo electrónico: acunasm@utalca.cl

Trabajo realizado en el marco del Proyecto Fondecyt No 11160064 , "Contenido esencial y límites del derecho-deber de cuidado personal de los hijos: propuesta de configuración integral", del que la autora es investigadora responsable.

Artículo recibido el 26.9.2017 y aceptado para su publicación el 15.1.2018. 


\section{INTRODUCCIÓN}

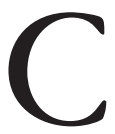

omo consecuencia de la relación paterno-filial nacen entre padres e hijos ciertos derechos, deberes y funciones que los vinculan, entre ellos el derecho-deber de cuidar a los hijos. Cuando los padres viven juntos este derecho-deber se ejercita ordinariamente como desenvolvimiento de la vida en común de la familia, y consecuencia normal de su ejercicio es la formación de una comunidad de vida. Tal realidad se altera cuando los padres viven separados.

La situación de los hijos cuyos padres no conviven se ha convertido en un tema de alta relevancia social, jurídica y política. El aumento de los nacimientos fuera del matrimonio así como la consolidación de la figura del divorcio explican en parte la actualidad de los aspectos humanos subyacentes y de los problemas propiamente jurídicos de aquella situación; otro tanto se advierte de instrumentos internacionales que interesan a la mejor protección de la familia y de los propios hijos. Si bien algunos instrumentos no son recientes, sí lo es la paulatina adaptación de los ordenamientos a las directrices que ellos imponen. Un lugar privilegiado lo ocupa la Convención de Derechos del Niño (CDN).

Gran parte de las recientes reformas de derecho familiar en diversos ordenamientos han ido fortaleciendo las figuras de cuidado personal por medio de la paulina consideración de los derechos de los hijos, el abandono progresivo de los estereotipos de género y la incorporación de la modalidad de cuidado personal compartido. Siguiendo esa tendencia legal, el mayor desarrollo doctrinal del cuidado personal cuando los padres no conviven, ha estado destinado a la valoración de las reglas de atribución, así como al examen de las modalidades de cuidado. No ocurre lo mismo con la determinación del contenido esencial del derecho-deber de cuidado personal; este es el problema jurídico con menor atención legal, doctrinal y judicial.

Este trabajo aborda la delimitación del contenido esencial del derecho-deber de cuidado personal de los hijos, para ello, la primera parte revisa críticamente el estado de la cuestión, y un segundo apartado se aboca al análisis de diversos elementos que contribuyen a deslindar el contenido del cuidado personal, el que desde ya puede advertirse, se ha reducido sustancialmente. Se finaliza con las conclusiones.

\section{ESTAdo DEL ARTE EN RELACIÓN CON EL CUIDAdo PERSONAL DE LOS HIJOS}

\section{Problemáticas en torno al contenido del cuidado personal}

A diferencia de lo que ocurre con la patria potestad o con el derecho de relación directa y regular, el legislador no define qué es el cuidado personal, ni lo dota de contenido. La ausencia de conceptualización legal conlleva que no se encuentre delimitado el ámbito de realidad protegido por el derecho, lo que es causa de complejidades y problemas a la hora de situar el cuidado en relación con otros derechos de la relación paterno-filial, como el uso de la vivienda familiar, la determinación de la pensión alimenticia y muy 
especialmente con el derecho-deber de relación directa y regular del padre no cuidador. A ello se suman posibles tensiones con los derechos de los hijos, en la medida que los temas de cuidado sean vistos exclusivamente desde la óptica de los padres.

La ausencia de definición y regulación legal del contenido del cuidado, ha provocado dispersión doctrinal a la hora de determinar su contenido y alcance. La literatura evidencia ausencia de uniformidad, con posturas que incluso no son consistentes con los actuales principios inspiradores de las relaciones personales paterno-filiales y con los derechos de los hijos; pero lo más notable del asunto es la amplia incidencia de la decisión de atribuir a un padre el cuidado de sus hijos por la estrecha relación que este tiene con otros derechos circundantes (derecho de relación directa y regular, patria potestad, derecho de alimentos, entre otros). La ley no aclara estos puntos, a lo que se suma la normal indefinición en las sentencias.

Las decisiones respecto de la atribución del cuidado personal de un hijo representan la puerta de entrada al ejercicio de otras funciones y a la determinación del modo de cumplimiento de otros deberes de la relación paterno-filial. Partiendo de la modalidad de cuidado, el juez deberá fijar o los padres habrán de pactar los restantes extremos que atañen a los hijos menores de edad. Un tema complejo es el de la toma de decisiones, esto es, la determinación de qué decisiones competen a ambos padres como derivación del vínculo filiativo, y cuáles corresponden en exclusiva al progenitor cuidador.

Lo expuesto deja ver un filón no agotado de cuestiones tanto conceptuales como prácticas en torno al contenido del cuidado que requieren ser cuidadosamente exploradas. Tal exploración debe tener presente que la dotación de contenido es una labor delicada, que en ningún caso puede implicar generar una lista cerrada y rígida de actuaciones o comportamientos del padre cuidador, por cuanto ello implicaría desconocer la naturaleza de las relaciones de familia y en particular de las paterno-filiales que tienen un carácter íntimo y muy individualizado, por tanto, el acercamiento debe hacerse desde unas ideas generales que otorguen suficiente amplitud de adaptación a los diversos casos.

\section{Regulación del cuidado personal de los hijos}

El cuidado personal de los hijos es una función tuitiva derivada de la relación de filiación, que viene a concretar en parte la preocupación fundamental de los padres señalada en el art. 222 CC. Normativamente se encuentra tratado en los arts. 224 a 227 CC, dentro del título De los derechos y obligaciones entre los padres y los hijos; en ellos no se define el cuidado personal, no se fija su contenido, ni se especifica qué atribuciones, deberes y facultades otorga a su titular. Ni las actuales normas, ni las que les precedieron, se pronuncian acerca del tema, lo que da cuenta de una carencia de regulación sistemática de un aspecto relevante de la autoridad parental, que impacta en el ámbito funcional de las relaciones paterno-filiales, esto es, en su ejercicio. Dicha carencia ha sido denunciada como parte de la explicación de por qué se percibe socialmente una asimetría tan radical entre la posición de los padres luego de una separación ${ }^{1}$. La determinación

\footnotetext{
1 TAPIA, 2013, p. 478.
} 
más igualitaria de quien asume el cuidado de los hijos, no soluciona los problemas de exclusión de uno de los padres en la medida que no esté claro qué facultades o atribuciones reporta a su titular; si el titular del cuidado personal sigue convencido de que tiene un poder absoluto -exclusivo y excluyente- acerca de aspectos sensibles de la vida de los hijos, los problemas de fondo no se habrán solucionado con las nuevas normas de atribución de cuidado por muy igualitarias o equitativas que aparezcan en el papel.

Para la adecuada apreciación de esta situación resulta pertinente revisar brevemente la regulación del cuidado personal de los hijos antes y después de la reforma de la Ley 20.680 de 2013, con enfoque principal en su contenido.

\section{2.a) Cuidado personal antes de la reforma de la Ley 20.680}

La Ley 19.585 concedió gran preponderancia al cuidado personal de los hijos dentro de las instituciones propias de la autoridad parental, a tal punto que esta última pasó a ser una categoría accesoria al cuidado ${ }^{2}$, convirtiendo a este en la figura central de la relación de filiación.

Si bien no se definió qué era el cuidado personal, el art. 224 CC hablaba del cuidado personal de la crianza y educación de sus hijos, con lo que dos de las más importantes funciones parentales aparecían ligadas al cuidado, siendo posible sostener que quien detentaba el cuidado tenía a su cargo la crianza y educación de los hijos ${ }^{3}$.

La modalidad de cuidado personal revestía enorme importancia en la centralidad misma de las relaciones paterno-filiales: quien tenía el cuidado personal no solo detentaba el deber abstracto de criarlo y educarlo, sino muy especialmente actuaciones prácticas concretas como decisiones en torno a su salud, colegio, deportes, amigos, religión, cercanía o distancia con determinados parientes, hábitos alimenticios o de higiene, etc., y, además, salvo acuerdo o decisión judicial contraria, quien tenía el cuidado personal ejercía también la patria potestad ${ }^{4}$.

El resto de la regulación del cuidado personal, referido a su ejercicio, es bien conocido: ejercicio de consuno en vida conjunta de los padres; ejercicio individual en caso de vida separada, con preferencia legal materna y posibilidad de modificación por acuerdo solemne o sentencia judicial de probarse maltrato, descuido u otra causa calificada cuando el interés del hijo lo hiciera indispensable. Los conflictos jurídicos en torno al cuidado se centraban en su titularidad, pues esta concedía un cúmulo de facultades al padre a quien se le atribuía, dejando al otro padre con un derecho residual a relacionarse con su hijo $^{5}$. Una de las principales observaciones a la regla legal de preferencia materna era que

${ }^{2}$ BARCIA, 2013, p. 24.

${ }^{3}$ Se aludía al cuidado de la crianza de los hijos y al cuidado de la educación. MezA, 1979, p. 519; López, 2001, p. 110; SCHмidT, 2004, p. 42 y RuZ, 2012, p. 462 y 463.

${ }^{4}$ Abeliuk, 2003, p. 321; ACuña, 2011, p. 380. Cfr. art. 245 inc. $1^{\circ}$ CC previo a la reforma de 2013.

${ }^{5}$ Se aludía al paradigma ancestral en el que se piensa que, producida la separación, los hijos deben ser criados por la madre, limitándose el padre a desempeñar un rol de proveedor por medio del pago de obligaciones alimenticias. Arancibia y Cornejo, 2014, p. 304. 
si bien permitía disminuir la judicialización en ausencia de acuerdos, peligrosamente generaba una concentración de poderes y facultades en uno de los padres privando al otro prácticamente de todos los efectos esenciales que configuran la relación de filiación 6 .

Siguiendo la parquedad legal, la doctrina se ocupaba principalmente de la revisión de las normas de atribución y escasamente de conceptualizar el cuidado personal, advirtiéndose incluso que no se puede delimitar claramente, pudiendo a lo más decirse que se relaciona con la idea de qué progenitor convive con los hijos ${ }^{7}$. Dentro de los autores que acometieron tal labor se entendía que el cuidado personal se refiere o es: el derecho paternal a la crianza, educación y establecimiento del menor de edad, o como el deber de alimentar, corregir y otorgar por lo menos una educación básica y un oficio de profesión al hijo ${ }^{8}$; el derecho de los padres de tener a sus hijos en su compañia 9 ; el Derecho de los padres a tener a sus bijos en su compañía proporcionándoles residencia, alimentos y educación ${ }^{10}$; aquel derecho puro de familia, que presuponiendo una convivencia inmediata y permanente con el menor, permite cumplir dinámicamente con los deberes de crianza y educación ${ }^{11}$; cuidado personal como tenencia fúsica y responsabilidad primera en su cuidado ${ }^{12}$; figura que comprende no solo la crianza y educación sino la realización de todo lo necesario para el desarrollo espiritual y material del hijo ${ }^{13}$; el derechodeber de los padres de criar, educar y tener a los hijos en su compañia con el fin de guiarlos en su desarrollo y realización material y espiritual ${ }^{14}$.

Las diversas conceptualizaciones en su mayoría concebían el cuidado personal desde la óptica de los padres, como un derecho de estos, con un contenido vinculado a la crianza y educación, adicionando en algunos casos algún otro atributo. Algunas definiciones se concentran solo en el aspecto material de la tenencia física o compañía. Cualquiera sea el caso, se entendía que las funciones de crianza y educación quedaban radicadas exclusivamente en el padre cuidador, lo que generaba en la ley y en la práctica, la marginación del otro padre.

\section{2.b) Regulación actual del cuidado personal}

A partir de la Ley 20.680 la regulación de la relación paterno-filial ha superado las normas que mantenían la preferencia en favor de la mujer; consolida el acuerdo como mecanismo decisorio prioritario; elimina las altas exigencias para que el juez pueda alterar el régimen de cuidado que estuviere vigente, contemplando criterios de resolución judicial de las disputas por la titularidad del cuidado que permiten que se haga una

\footnotetext{
${ }^{6}$ ACUÑA, 2011, p. 385.

${ }^{7}$ LATHRop, $2013 \mathrm{a}$, p. 90.

8 Bavestrello, 2003, p. 61.

9 SCHMidT y Veloso, 2001, p. 273.

${ }^{10}$ Gómez De la Torre, 2007, p. 135.

11 Ascencio, 2000, p. 42.

12 Domínguez, 2010, p. 1.

${ }^{13}$ Lathrop, 2005, p. 6.

${ }^{14}$ ACUÑA, 2011, p. 379.
} 
revisión de los elementos que son centrales para la verificación del interés superior del hijo en el caso concreto; incorpora la modalidad de cuidado personal compartido; fortalece el derecho de relación directa y regular; reconoce el derecho del niño a relacionarse con sus abuelos; y equilibra algunos aspectos de la patria potestad.

Pese a las carencias particulares que pudieran presentar las específicas regulaciones, es innegable la trascendencia de estas en pos del bienestar de los hijos y del establecimiento de relaciones más equitativas entre los padres. Sin embargo, las normas no se pronuncian sobre el contenido del derecho-deber de cuidado; los arts. 224 y 225 CC se dedican a fijar las reglas de titularidad y modalidades del cuidado personal en las distintas hipótesis posibles (según si los padres viven juntos o separados), sin delimitación de las implicancias prácticas que acarrea detentar el cuidado personal de un hijo, dando lugar a un vacío normativo relevante, en cuanto es el ejercicio del derecho el que genera conflictos entre los padres y puede lesionar los derechos de los hijos.

La doctrina posterior a la reforma ha avanzado algunas ideas; se sostiene que el cuidado personal se refiere al conjunto de obligaciones y facultades derivadas de convivir o compartir la vida cotidiana de los hijos ${ }^{15}$; lo que, aunque aparezca limitado al criterio de "la vida cotidiana", resulta de una vaga amplitud: ¿Cuáles son ese conjunto de obligaciones y facultades? ¿Qué cuestiones forman parte de la vida cotidiana? También se ha dicho que el cuidado personal de los hijos se refiere a los cuidados y atenciones diarias y habituales del hijo ${ }^{16}$, lo que también exige hacer precisiones.

\section{Elementos PARA la CONSTRUCCión DEL CONTENIDO ESENCIAL DEL CUIDADO PERSONAL DE LOS HIJOS}

Si bien la reforma gestada por la Ley 20.680 ha sido planteada como una que introduce modificaciones al CC y a otros cuerpos legales con el objeto de proteger la integridad del menor en caso de que sus padres vivan separados, lo cierto es que de manera significativa sus normas y principios comportan una suerte de "reinvención" del cuidado personal y de la relación paterno-filial. Pese a no contemplar definición ni precisión del contenido del cuidado, sí proporciona algunas piezas que adecuadamente conjugadas permiten hacer una delimitación de su contenido esencial actual. En función de ello se propone el análisis de los siguientes elementos.

\section{Principio de corresponsabilidad parental}

La Ley 20.680 introdujo este principio jurídico, cuyo antecedente más directo se encuentra en el art. $18 \mathrm{CDN}$, conforme con este, ambos padres tienen obligaciones comunes en lo que respecta a la crianza y el desarrollo del niño. Incumbirá a los padres, o en su caso, a

\footnotetext{
${ }^{15}$ LEPIN, 2013, p. 290. El autor sigue la definición del art. 648 del Código Civil y Comercial argentino.

${ }^{16}$ ACUÑA, 2016a, p. 487.
} 
Los representantes legales la responsabilidad primordial de la crianza y el desarrollo del niño. Su preocupación fundamental será el interés superior del niño ${ }^{17}$. Siguiendo esa idea matriz, el art. 224 CC expresa que el cuidado de los hijos se basará en el principio de corresponsabilidad, en virtud del cual ambos padres, vivan juntos o separados, participarán en forma activa, equitativa y permanente en la crianza y educación de sus bijos.

El principio significa que ambos padres se responsabilizan y participan, concurren y asumen en común las funciones de crianza y educación de los hijos. Las expresiones distribución o reparto que emplean algunas definiciones, por muy equitativo que sea, choca frontalmente con lo que se quiere comunicar, pues en realidad si los padres se reparten las funciones y uno se ocupa de la crianza habitual y otro de los esparcimientos, uno de los gastos y otro de la gestión, realmente no hay corresponsabilidad ${ }^{18}$.

El principio impone a los padres la participación en la vida de sus hijos; no se trata de un ejercicio opcional. Si bien respecto de los hijos la responsabilidad parental es un deber, mirado en relación con el Estado, implica una posición privilegiada en cuanto a la educación y crianza, justificada bajo el supuesto de que la mayoría de los padres quieren el bien de sus hijos, tanto así que se ocupan del cuidado, crianza y educación porque están interesados en el bienestar de sus hijos y no debido a la imposición de un deber legal ${ }^{19}$. Si dicha justificación en el caso concreto no está presente, como ocurre en casos de negligencia parental o maltrato, los padres pierden tal privilegio ${ }^{20}$.

El principio opera tanto cuando los padres viven juntos como cuando viven separados, resultando evidente que sus implicancias más importantes se manifiestan en vida separada, particularmente cuando hay desacuerdos. En ese momento se hace particularmente relevante entender que si bien el legislador puede optar por un fraccionamiento de las relaciones (cuidado personal individual para un padre y relación directa y regular para el otro), la corresponsabilidad se erige como un contensor que aspira a mantener a ambos padres participando y responsabilizándose de la vida de sus hijos.

Aunque se ha denunciado una cierta inconsistencia entre la consagración del principio de corresponsabilidad parental y la regulación del cuidado personal individual ${ }^{21}$, el primero tiene un campo de influencia mucho más amplio que el solo cuidado compartido,

${ }^{17}$ La Convención sobre la Eliminación de todas las Formas de Discriminación contra la Mujer, marca un punto de inflexión en materia de la responsabilidad de los padres, al reconocer la función del padre y madre en la familia y en la educación de los hijos, y afirmar que el papel de la mujer en la procreación no debe ser causa de discriminación, sino que la educación de los niños exige la responsabilidad compartida entre hombres y mujeres y la sociedad en su conjunto (preámbulo). Su art. 5 letra b) alude al reconocimiento de la responsabilidad común de hombres y mujeres en cuanto a la educación y al desarrollo de sus hijos, en la inteligencia de que el interés de los hijos constituirá la consideración primordial en todos los casos.

18 ACUÑA, 2013, p. 29.

${ }^{19}$ BRIDGEMAN, 2017, p. 61.

${ }^{20}$ EekelaAr, 2017, p. 30.

${ }^{21}$ Apunta a tal inconsistencia BARCIA, 2013, p. 33. En relación con ordenamientos europeos se afirma que la apreciación generalizada de que la custodia compartida está implantada en los países de la Unión Europea es inexacta y encuentra explicación en la errada equiparación que se ha hecho entre "custodia compartida" y responsabilidad parental, que son en realidad categorías jurídicas distintas; lo que gran parte de esos países regulan es la responsabilidad parental que en la gran mayoría de ellos se comparte permitiendo 
en el que incide relevantemente ${ }^{22}$. La Ley 20.680 se orienta en aquella dirección al señalar en el art. 229 inc. $4^{\circ} \mathrm{CC}$ que el principio opera cuando hay distribución asimétrica del cuidado personal de los hijos, con lo que el progenitor que no tiene el cuidado debe igualmente participar en forma activa, equitativa y permanente en la crianza y educación de sus hijos ${ }^{23}$. En torno a la perfecta compatibilidad entre la corresponsabilidad y el cuidado personal en uno de los padres se han pronunciado la Corte Suprema ${ }^{24}$, el Tribunal Constitucional ${ }^{25}$ y parte de la doctrina nacional reciente ${ }^{26}$.

Desde otro ángulo se señala que el principio carecería de efectividad, que no existe acción para exigir su concreción por parte del padre no custodio ${ }^{27}$, que el juez estaría impedido de hacerlo efectivo ${ }^{28}$. La ausencia de una expresa y específica acción desde mi punto de vista si bien es una cuestión que ensombrece el panorama, no es un obstáculo absoluto. Aunque es efectivo que los mecanismos para hacer cumplir en general los deberes paterno-filiales son imperfectos, el juez de familia cuenta con herramientas para hacer efectiva la corresponsabilidad en consideración al interés superior de los hijos ${ }^{29}$, lo que puede concretarse con mejores especificaciones en las sentencias.

En los hechos es indudable que el padre no cuidador tendrá varios problemas para hacer real su participación: algunos determinados por la ausencia de especificaciones en la sentencia acerca de ciertas facultades o decisiones que no queda claro si son propias del cuidado o deben ejercitarse en el marco de la corresponsabilidad; otros se originan por la escasa convivencia de estos progenitores con sus hijos, pues aunque en términos estrictamente legales aquel padre tenga reconocida su participación, su mermada relación influirá en el cumplimiento de los deberes; por el contrario, será más hacedero un desempeño adecuado para el padre que tiene el cuidado personal.

Dentro de los avances en la materialización del principio se encuentra el Ordinario 27 de 2016 de la Superintendencia de Educación, conforme con esto, los sostenedores, las autoridades y en general todos los funcionarios de establecimientos educacionales, en relación con el padre y madre, aunque no sean apoderados y no tengan el cuidado personal de sus hijos, están obligados a garantizar y respetar su derecho a asociarse y

que ambos progenitores tengan parte activa en la toma de decisiones fundamentales respecto de sus hijos. Aramburu, 2006, p. 53.

${ }^{22}$ No solo en situaciones de cuidado compartido los padres deben compartir en forma equitativa los deberes y derechos respecto de los hijos, sino cualquiera sea el régimen de cuidado o visitas. TAPIA, 2013 , p. 480.

23 ACUÑA, 2013, p. 30.

${ }^{24}$ Corte Suprema, 4.9.2014, rol 21334-2014.

25 Tribunal Constitucional, 16.6.2015, rol No 2699-14-INA.

${ }^{26}$ Quintana, 2014, p. 253; Rodríguez, 2014, p. 80.

${ }^{27}$ LEPIN, 2013, p. 295.

${ }^{28}$ Etcheberry, 2014, p. 65; OtÁrola, 2013, p. 19.

29 Así, conociendo de procesos de separación o divorcio, al evaluar los acuerdos presentados por los cónyuges el juez debe verificar si resguardan el interés superior de los hijos y puede proceder en la sentencia a subsanar sus deficiencias o modificarlos si fueren incompletos o insuficientes (arts. 27 y 31 Ley de Matrimonio Civil). 
participar en las organizaciones de padres y apoderados; su derecho a participar en las reuniones de apoderados; su derecho a tener acceso a los informes educativos del alumno de la misma forma que el padre o madre que está registrado como apoderado ante el establecimiento y su derecho a participar en actividades extraescolares.

La concreción del principio implica que si bien decisiones de todos los días deben ser tomadas por quien tiene el cuidado, las decisiones más importantes deben ser adoptadas de común acuerdo; dentro de ellas claramente debe estar la decisión respecto de la educación del hijo ${ }^{30}$. La determinación de cuáles son decisiones propias de la responsabilidad común requiere ser precisado caso a caso por la ausencia de especificaciones legales $^{31}$. No es propósito de este trabajo ahondar en estas cuestiones más propias de la corresponsabilidad y que requieren otros análisis, pero sí interesa decir que estas especificaciones podrían venir señaladas en las sentencias que resuelven procesos matrimoniales o causas de cuidado personal o de relación directa y regular, o en los acuerdos de los propios padres. La Corte Suprema ha adelantado un criterio para esta determinación, como se verá.

La corresponsabilidad exige un involucramiento directo y continuo de ambos padres en la crianza del hijo, abarcando desde el derecho-deber que tiene cada padre para definir cómo será criado su hijo y qué valores serán transmitidos en un ambiente de cariño que incentive su desarrollo intelectual, hasta la toma de decisiones respecto de su enseñanza, comprendiendo aspectos académicos y sociales ${ }^{32}$. El ejercicio no se estanca en las funciones recogidas en la ley (crianza y educación), sino que incluye la capacidad de los padres para vincularse con sus hijos, responder a sus necesidades, establecer modelos de crianza y transmitir afectos ${ }^{33}$. La responsabilidad parental da cuenta de obligaciones continuadas que exigen una conducta permanente de los padres; el interés de los hijos constituye el límite de su actuar, por tanto, la libertad de criar y educar a los hijos no es ilimitada; pueden existir restricciones en protección del interés de los hijos ${ }^{34}$.

Los amplios términos en que es reconocido el principio de corresponsabilidad parental parecen restringir el contenido del cuidado personal a un elemento más bien de carácter material, referido a quién vivirá con el hijo y lo tendrá bajo su cuidado directo.

30 Etcheberry, 2014, p. 64; Negroni, 2014, p. 116. Lepin reduce el contenido del principio a aspectos de la vida diaria o cotidiana del hijo, mismos aspectos que en su concepto son propios del cuidado personal, con lo que no se advierte en qué radica para el autor la diferenciación entre el principio y el cuidado personal. LePIN, 2013, p. 295.

${ }^{31}$ El Código Civil y Comercial argentino dentro del ejercicio de la responsabilidad parental proporciona un listado de actos que requieren el consentimiento expreso de ambos progenitores (art. 645), los que pueden ser empleados de modo referencial. Si uno de los progenitores no da su consentimiento o media imposibilidad para prestarlo, resuelve el juez y, cuando el acto involucra a hijos adolescentes, es necesario su consentimiento expreso.

32 Arancibia y Cornejo, 2014, p 303.

33 SAllés y Ger, 2011, pp. 25 y ss.; Bridgeman, 2017, p. 57.

${ }^{34}$ Acerca de algunas limitaciones a la actuación de los padres se puede ver LATHRop, 2017, p. 242. 


\section{Modificación de la referencia al cuidado personal en el artículo 224 del CC}

Cuando los padres viven juntos toca de consuno a los padres, o al padre o madre sobreviviente, el cuidado personal de sus hijos. Previo a la Ley 20.680, el art. 224 CC establecía: toca de consuno a los padres, o al padre o madre sobreviviente, el cuidado personal de la crianza y educación de sus hijos. Ambas normas parecen similares, pero no lo son, pues si bien recogen la solución evidente para el caso de vida conjunta de los padres (ejercicio de consuno), no es menos cierto que, antes de la reforma el cuidado personal aparecía indisolublemente ligado a la crianza y educación de los hijos, de tal modo que podía estimarse que estas funciones eran su contenido esencial.

El actual texto elimina tal asociación y radica dichas funciones en la responsabilidad común de los padres. El cuidado personal parece reservado a los cuidados y atenciones diarias y habituales de los hijos ${ }^{35}$. Lo anterior, sumado a la relevancia del principio de corresponsabilidad parental, lleva a concluir que efectivamente se ha reducido el ámbito de realidad cubierto por el cuidado personal ${ }^{36}$, al menos en la letra de la ley; en la realidad aplicativa pareciera existir aún la percepción de que el cuidado personal otorga más facultades.

La idea de reducción de contenido se ha venido desarrollando en otras latitudes, estimándose que el contenido de la guarda o custodia debe quedar limitado a la convivencia o tenencia del menor y debe desaparecer la creencia errónea de que el progenitor custodio es el que ostenta el poder sobre el hijo ${ }^{37}$. En el ordenamiento español por ejemplo, la guarda y custodia se identifica con el cuidado y atención diario que se ejerce mediante la convivencia habitual ${ }^{38}$; engloba el cuidado directo y para su correcto desempeño implicaría una situación de convivencia con el hijo ${ }^{39}$; no se confunde la patria potestad con la guarda y custodia ${ }^{40}$; esta es un concreto aspecto del ejercicio de la primera, que se vincula con el cuidado diario ${ }^{41}$; y por tanto abarca las obligaciones que se originan en esa vida diaria, por ello el progenitor guardador decide en la esfera ordinaria o urgente del hijo, requiriendo la presencia del otro progenitor para concluir actos que excedan de aquella ${ }^{42}$. El Código Civil y Comercial argentino, también expresa

35 ACUÑA, 2016a, p. 489.

36 BARCIA, 2013, p 33.

37 Así Viñas, 2012, p. 5; García, 2015, p. 45.

38 SAN SEgUndo, 2010, p. 138.

39 RABADÁN, 2011, p. 61.

${ }^{40}$ Gete-Alonso y Solé, 2015, p. 456; Serrano, 2010, p. 56; Ragel, 2001, p. 285.

${ }^{41}$ Morán, 2010, p. 79.

42 Gullarte, 2014, p. 23-24; Gete-Alonso y Solé, 2015, p. 456; Rabadán, 2011, p. 61. La idea de un contenido esencialmente material (convivencia) de la guarda, si bien es mayoritaria, no es única. También se ha propuesto en torno al concepto dos acepciones: la primera restringida, donde la guarda y custodia de los hijos consiste en el cuidado personal, directo, diario y continuo que se entrega por medio de la convivencia; la segunda más amplia, donde la guarda y custodia comprende el conjunto de prestaciones de carácter personal a través de las cuales se cumplen los deberes parentales, sin restringir su contenido al hecho de vivir con el hijo, por lo que resulta más cercana a nuestra autoridad parental. López, 2011, p. 275. 
un contenido reducido al identificar el cuidado personal con los deberes y facultades de los progenitores referidos a la vida cotidiana del hijo (art. 648) ${ }^{43}$ y necesariamente comprende la convivencia con el progenitor ${ }^{44}$.

Conforme con nuestra regulación pertenecen a ambos padres todas las funciones tuitivas relativas a crianza y educación que no dependen de la convivencia diaria, especialmente la toma de las decisiones de mayor trascendencia en relación con los hijos, pues estas son derivación de la relación paterno-filial y a ellas están vinculados ambos padres. El progenitor no cuidador mantiene intactas las facultades derivadas de la relación paterno-filial; en abstracto, la modalidad de repartición del tiempo del niño no tiene ningún efecto jurídico diferenciador en las calidades de padre y madre; el cuidado personal solo define el deber de mantener a un hijo en el hogar y atender sus necesidades diarias, aunque en la práctica, como he dicho, es evidente que aquel tendrá mayor dificultad para el cumplimiento de los deberes inherentes a ella.

La Corte Suprema ha expresado que los arts. 225 y 225-2 CC -en plena consonancia con las tendencias comparadas y los pactos internacionales suscritos por Chile-, "han desplazado el foco desde la inhabilidad como una forma de reprobación o sanción de los padres, hacia una interpretación centrada en el niño como sujeto de derechos, respecto de quién ambos padres deben tomar parte activa en las decisiones fundamentales relativas a su crianza y desarrollo, con el interés superior del hijo como preocupación esencial" 45 . La Corte introduce el criterio de las "decisiones fundamentales" respecto del hijo, que competen a ambos padres, no solo al cuidador ${ }^{46}$.

Al mismo tiempo que el cuidado personal ha sufrido una transformación estructural en lo que podía ser considerado su núcleo duro (crianza y educación), se refuerza su carácter de función básica y elemental dentro de la autoridad parental ${ }^{47}$. La finalidad que lo guía sigue siendo el interés superior de los hijos, lo que resulta particularmente relevante en términos de su contenido y ejercicio porque un derecho -y muy especialmente un derecho-deber- se encuentra limitado por su finalidad.

\section{Criterios de atribución del cuidado personal}

Consciente de que los pronunciamientos judiciales acerca del cuidado personal repercuten notablemente en la vida de progenitores e hijos, la ley obliga a los jueces a

\footnotetext{
43 No es solo la guarda material, sino también es estar, velar y hacer por el hijo. MAZZiNGHI Y MAZZINGHI, 2016, p. 48.

${ }^{44}$ Mizrahi, 2016, p. 365.

${ }^{45}$ Corte Suprema, 11.7.2017, rol 4827-2017 y 19.7.2017, rol: 4951-2017.

${ }^{46}$ En España las Audiencias Provinciales hacen pronunciamientos expresos sobre la participación en la toma de decisiones relativas a los hijos. AP Asturias, 207/2010, de 2 junio (JUR 2010\250698); AP A Coruña, 147/2012, de 23 de marzo (id. vlex: VLEX-365849250).

${ }^{47}$ Para un nuevo texto constitucional que considere los derechos de los NNA se propone tener en cuenta, entre otras cuestiones, la consagración del cuidado como función básica. LATHrop, 2017, p. 248.
} 
un análisis acabado de todas las circunstancias que confluyen en el caso ${ }^{48}$; y los obliga a motivar adecuadamente sus decisiones, labor que requiere el ejercicio efectivo del rol tutelar del juez y no se satisface con la alusión al interés superior del niño en abstracto como una declaración retórica, sino que importa considerar el interés en concreto. En el establecimiento del régimen y ejercicio del cuidado personal, el juez debe considerar y ponderar conjuntamente los criterios y circunstancias del nuevo art. 225-2 CC; a partir de ahí, el interés del hijo ya no podrá ser asimilado automática y mecánicamente a la custodia materna en todos los casos; no puede asociarse exclusivamente con un bienestar económico; y no corresponde tampoco que los jueces sin más se conformen con mantener el cuidado personal en aquel de los padres con quien los hijos están conviviendo, por cuanto la regla legal es provisoria y no un estándar de priorización legal a que deba someterse el juez. Lo único que interesa es desentrañar cuál de los padres está en condiciones de proveer mejor a su interés superior; para ello los jueces deben basarse en la evidencia acerca de los datos objetivos contenidos en la prueba recogida ${ }^{49}$.

En lo que interesa a este trabajo, el art. 225-2 CC dispone que en el establecimiento del régimen y ejercicio del cuidado personal, se considerarán y ponderarán conjuntamente, entre otros: b) La aptitud de los padres para garantizar el bienestar del hijo y la posibilidad de procurarle un entorno adecuado, según su edad; c) La contribución a la mantención del hijo mientras estuvo bajo el cuidado personal del otro padre, pudiendo hacerlo; d) la actitud de cada uno de los padres para cooperar con el otro, con el fin de asegurar la máxima estabilidad al hijo y garantizar la relación directa y regular, para lo que considerará especialmente lo dispuesto en el inciso quinto del artículo 229; y e) La dedicación efectiva que cada uno de los padres procuraba al hijo antes de la separación $y$, especialmente, la que pueda seguir desarrollando de acuerdo con sus posibilidades.

La norma es evaluada en general positivamente ${ }^{50}$ en cuanto las circunstancias y criterios contribuyen a contrarrestar la arbitrariedad que pudiera presentarse por la abstracción del principio del interés superior del hijo ${ }^{51}$; los criterios sirven para construir o integrar en concreto su interés superior ${ }^{52}$; por otro lado, se desvincula el cambio de cuidador del carácter sancionatorio que tenía la decisión judicial antes de la reforma ${ }^{53}$.

Una atenta lectura permite advertir, además, que el legislador ha incorporado al léxico de la relación paterno-filial exigencias concretas de comportamientos con expresiones específicas como colaborar o garantizar el bienestar de los hijos, entre otras. Estas expresiones van perfilando un modo deseable de actuación del padre cuidador. A partir

48 Quintana, 2014, p. 243.

${ }^{49}$ Corte Suprema, 23.5.2017, rol 9986116.

50 Se ha advertido de los peligros de una errónea aplicación de algunos criterios. Así, respecto de la letra d) del art. 225-2, se estima que podría llevar a la jurisprudencia nuevamente por el camino de la preferencia materna, al menos en aquellos hogares en que la madre desempeña el trabajo doméstico y el padre el remunerado. Turner, 2013.

${ }^{51}$ Lathrop, 2013b, p. 7.

52 Etcheberry, 2014, p. 69; Rodríguez, 2014, p. 90.

53 TAPIA, 2013, p. 488. 
de ahí es posible sostener que para la ley el cuidado de un hijo supone (en términos de contenido), entre otras cosas, garantizar el bienestar del hijo, procurarle un entorno adecuado, dedicación efectiva y vinculación afectiva, cooperar con el otro padre con el fin de asegurar la máxima estabilidad al hijo y garantizar la relación directa y regular ${ }^{54}$.

La ley que contribuye en las construcciones sociales y en las interpretaciones individuales, ha fijado aquí -al igual que cuando conceptualiza la corresponsabilidad parental- estándares mínimos de actuación de los padres elevando el patrón de exigencias.

Otro aspecto que aparece de dichos criterios y circunstancias es que el ejercicio del cuidado se encuentra funcionalizado. Hoy más que antes se hace manifiesto que la actuación del cuidador se encuentra condicionada, supeditada o puesta al servicio del bienestar del hijo, respecto de esto, los padres aparecen como garantes ${ }^{55}$.

\section{El derecho de relación directa y regular}

El contenido del cuidado personal no puede ser contemplado de manera aislada; hay que ponerlo en relación con los restantes derecho-deberes de la relación paterno-filial, especialmente con el derecho de relación directa y regular, que constituye la forma que los hijos tienen para relacionarse con el padre no cuidador. Ambos institutos miran al interés del hijo; se trata de dos formas de relacionarse con ellos, uno de modo habitual y constante, el otro según la periodicidad que se determine en el régimen específico ${ }^{56}$. El interés protegido es el mismo, el desarrollo integral del hijo por medio de la preservación de su relación con ambos progenitores.

El derecho de relación directa y regular del art. 229 CC ha sido completamente rediseñado por la Ley 20.680, fortaleciéndolo de modo coherente con el principio de corresponsabilidad parental; hoy se entiende por relación directa y regular aquella que propende a que el vínculo familiar entre el padre o madre que no ejerce el cuidado personal y su bijo se mantenga a través de un contacto periódico y estable. Su nuevo inc. $4^{\circ}$, conforme con esto, el juez debe asegurar la mayor participación y corresponsabilidad de los padres en la vida del hijo, se alinea a la tendencia creciente dirigida a sostener que el derecho a mantener un régimen de comunicación no solo implica asignar contacto y comunicación, sino

${ }^{54}$ No es extraña la consideración legal de deberes expresos de colaboración. En Argentina, donde el cuidado individual es excepcional, en los casos en que opera, se regulan deberes de colaboración y de información respecto de cuestiones de educación, salud y otras relativas a la persona y bienes del hijo (arts. 652 y 653). Para los efectos de decidir el cuidado individual el juez debe ponderar, entre otras cuestiones, la prioridad del padre que facilita mantener un trato regular con el otro (art. 653). En Italia el juez puede confiar la custodia a uno de los padres cuando el cuidado compartido es contrario al interés del niño, en cuyo caso el padre al que se confían en exclusiva los hijos tiene el ejercicio exclusivo de la responsabilidad parental, lo que se atempera con dos medidas: las decisiones de mayor importancia para los niños deben ser adoptadas por ambos padres; y el padre no cuidador tiene el derecho y el deber de supervisar su instrucción y educación pudiendo recurrir al juez cuando considere que se han tomado decisiones perjudiciales a los intereses del hijo (art. 337 quater Código Civil italiano).

55 ACUÑA, 2014, p. 63 y ss.

56 Así lo entiende Rodríguez, 2010, p. 87. 
también el derecho a participar activamente en las decisiones relevantes de la vida del hijo $^{57}$. Bien podría concluirse que la diferencia esencial entre el progenitor cuidador y el padre que no tiene el cuidado, no serían tanto las funciones que se les otorgan como sí los tiempos de estancia de los hijos en su compañía; cualquiera sea el caso, lo que sí resulta indiscutible es que el derecho de relación tiene hoy un contenido más rico y complejo del que le fuera tradicionalmente asignado, permitiendo por su ejercicio cumplir funciones familiares en un contexto de responsabilidad parental ${ }^{58}$.

Así regulado el derecho de relación y puesto en concordancia con el criterio del art. 225-2 letra d) CC, genera para el progenitor cuidador tanto deberes positivos como negativos: el titular del cuidado personal debe cooperar con el otro (padre), con el fin de asegurar la máxima estabilidad al bijo y garantizar la relación directa y regular (deber positivo) y debe, al mismo tiempo, conforme con el inc. $5^{\circ}$ del art. 229 CC no obstaculizar el régimen de relación directa y regular que se establezca a favor del otro padre (deber negativo) ${ }^{59}$.

La determinación del régimen de relación directa y regular implica que la posición jurídica del padre cuidador se caracteriza por una situación de deber jurídico, cuyas cargas principales son cooperar con el otro padre, asegurar la máxima estabilidad del hijo, garantizar la relación directa y regular y no obstaculizar su ejercicio. La cooperación como parte del ejercicio del cuidado personal viene impuesta por ley; la obstrucción al ejercicio del derecho de relación es una conducta antijurídica, un ejercicio inadecuado o abusivo del cuidado personal con consecuencias jurídicas ${ }^{60}$.

\section{Consideración de los hijos en las relaciones de familia}

Todo análisis que se haga del cuidado personal resulta incompleto si no se incorpora la perspectiva de los hijos como interesados y protagonistas fundamentales del derecho. Resulta pertinente, por tanto, explorar algunas disposiciones de la CDN que imponen nuevos estándares a las relaciones paterno-filiales.

En términos generales, la Convención reconoce que el niño, para el pleno y armonioso desarrollo de su personalidad, debe crecer en el seno de la familia, en un ambiente de felicidad, amor y comprensión (Preámbulo); que tiene derecho a ser cuidado por sus padres y a preservar sus relaciones familiares (arts. 7 y 8); que los Estados Partes deben tener en cuenta los derechos y deberes de sus padres y deben respetar las responsabilidades, los derechos y los deberes de estos (principalmente) de impartirle, en consonancia con la evolución de sus facultades, dirección y orientación apropiadas para que ejerza sus derechos (art. 5), reconociendo que ambos padres tienen obligaciones comunes en lo

57 TAPIA, 2013, p. 490.

58 ACUÑA, 2014, p. 54.

59 En España se postula que el custodio debe fomentar, favorecer y facilitar los contactos del hijo con el otro padre. Ragel, 2003, p. 116; De La Iglesia, 2008, p. 2514.

${ }^{60}$ Respecto de dichas consecuencias se puede consultar EtCHEberry, 2014, p. 71 y 72; ACUÑa, 2016b; ACUÑa, 2017, p. 411 y ss. 
que respecta a su crianza y desarrollo (art. 18). En lo particular, dos cuestiones resultan directamente relevantes.

5.a) Interés superior de los hijos

Conforme con el art. 222 CC "la preocupación fundamental de los padres es el interés superior del hijo, para lo cual procurarán su mayor realización espiritual y material posible, y lo guiarán en el ejercicio de los derechos esenciales que emanan de la naturaleza humana de modo conforme a la evolución de sus facultades”, de ello resulta una categórica afirmación: el interés jurídicamente tutelado en la regulación civil de las relaciones paterno-filiales es uno solo: el interés superior de los hijos ${ }^{61}$.

El ejercicio de todos los derecho-deberes derivados de la relación paterno-filial (cuidado personal, educación, facultad de corrección, derecho de relación directa y regular, etc.) conlleva una actuación en interés de $\operatorname{los}_{\text {hijos }}{ }^{62}$. Su ejercicio no queda a discreción del progenitor titular, ni a merced del beneplácito del que ejerce el cuidado personal ${ }^{63}$.

El principio de interés superior de los hijos en las relaciones paterno-filiales fue introducido por la Ley 19.585 limitado a dos niveles ${ }^{64}$ : en general en el art. 222 inc. $2^{\circ}$ (actual inc. $1^{\circ}$ ) y luego, como criterio para decidir la entrega judicial del niño a uno de los padres (antiguo art. 225 inc. $3^{\circ}$ CC). La Ley 20.680 amplió el ámbito de influencia del principio realzando su carácter transversal.

El contenido del interés del niño, como es sabido, debe determinarse en cada caso concreto ajustándose a la situación específica del niño, sus necesidades personales y su momento evolutivo. La Observación General No 14 (2013) del Comité de los Derechos del Niño, considera que "Al evaluar el interés superior del niño, el juez debe tener en cuenta el derecho del niño a conservar la relación con ambos progenitores, junto con los demás elementos pertinentes para el caso”. Durante la tramitación de la Ley 20.680, en el primer informe de la Comisión de Constitución, se enfatizó que el interés superior del niño debe verificarse por parte del juez en el caso concreto y no debe basarse en supuestos o presunciones generales respecto del bienestar de aquel ${ }^{65}$. La Corte Interamericana de Derechos Humanos ha dicho que su determinación en casos de cuidado debe hacerse a partir de la evaluación de los comportamientos parentales específicos y su impacto

${ }^{61} \mathrm{E}$ interés superior del hijo representa hoy el punto fundamental de la reglamentación de la familia: LATHROP, 2008, p. 25.

${ }^{62}$ En igual sentido RodríGuez, 2010, p. 16.

${ }^{63}$ El Código Civil francés entiende la autoridad parental como un conjunto de derechos y deberes cuya finalidad es el interés del niño (art. 371-1); en Argentina también se la concibe para la protección, desarrollo y formación integral del hijo (art. 638); por su parte el Código Civil español declara que la patria potestad, como responsabilidad parental, se ejercerá siempre en interés de los hijos, de acuerdo con su personalidad, y con respeto a sus derechos, su integridad física y mental (art. 154).

64 Turner, 2013.

65 Historia de la Ley 20.680. 
negativo en el bienestar y desarrollo del niño, los daños o riesgos reales y probados, y no especulaciones o imaginarios ${ }^{66}$.

La CDN contiene elementos para determinar cuál es el interés superior de un niño en el ámbito de su cuidado personal: la identidad del niño, que incluye la preservación del entorno familiar y el mantenimiento de relaciones con su familia (arts. 8 y 9); y la opinión del niño (art. 12), que debiera ser escuchada no solo por el juez, sino también por los padres. La legislación nacional, salvo en el caso del derecho de relación directa y regular ${ }^{67}$, únicamente considera el deber del juez de oír a los niños, en una materia que exige un protagonismo mayor de los hijos ${ }^{68}$. Un buen modelo al respecto aparece en el inc. final del art. 371-1 del CC francés al disponer Les parents associent l'enfant aux décisions qui le concernent, selon son âge et son degré de maturité (Los padres harán partícipe al niño de las decisiones que le conciernen, teniendo en cuenta su edad y su grado de madurez); algo similar al final del art. 154 del CC español ${ }^{69}$.

\section{5.b) Derecho a relacionarse con ambos padres}

El ejercicio de la autoridad parental se ha visto enriquecido por el derecho del niño a mantener relaciones con ambos padres y el derecho de estos últimos a tener un lugar en la vida cotidiana del niño ${ }^{70}$. La CDN establece que los Estados Partes respetarán el derecho del niño que esté separado de uno o de ambos padres a mantener relaciones personales y contacto directo con ambos de modo regular, salvo si ello es contrario al interés superior del niño (art. 9.3). Esta disposición es reconocida como aquella que afirma la coparentalidad ${ }^{71}$. Íntimamente vinculado con ella se encuentra el art. 7.1 CDN que establece el derecho del niño a ser cuidado por ellos. El derecho del niño a no ser separado de sus padres, implica que su interés superior reclama que crezca en compañía de ambos padres y que cada uno de ellos cumpla sus respectivos e igualmente importantes papeles en la crianza, salvo, cuando circunstancias particularmente graves autorizan la separación por ser contrarias a su interés o cuando la vida con ambos padres se hace imposible por vivir estos separados ${ }^{72}$.

El principio de coparentalidad se encuentra garantizado también en la Carta Europea de los Derechos del Niño: "Todo niño tiene derecho a gozar de sus padres. El padre y madre tiene una responsabilidad conjunta en cuanto a su desarrollo y educación...". "En caso de separación de hecho, legal divorcio o nulidad, el hijo tiene derecho a mantener

\footnotetext{
${ }^{66}$ CIDH, 24.2.2012, Átala Riffo y niñas vs Chile.

${ }^{67}$ Cfr. inc. tercero del 229 CC.

${ }^{68}$ Cfr. art. 225-2 letra f); art. 227 y art. 242 CC.

${ }^{69}$ Art. 154 CC español, párrafo $4^{\circ}$ : Si los hijos tuvieren suficiente madurez deberán ser oídos siempre antes de adoptar decisiones que les afecten.

70 Tовón, 2010, p. 80.

${ }^{71}$ Entre otras, MuÑoz, 2011, p. 159; LATHrop, 2008, p. 28.

72 Salanova, 1995 , p. 231 y ss.
} 
contacto directo y permanente con los dos padres, teniendo ambos las mismas obligaciones" (arts. 8.11 y 13).

Subyace a la normativa jurídica interna relativa al cuidado personal de los hijos, por un lado, la consideración, prima facie, de ser los padres quienes están en mejor posición de asegurarles la mayor realización espiritual y material posible y, por otro, el derecho de los hijos a ser criados y cuidados por sus padres; la asunción por terceros del cuidado constituye una situación de excepción que amerita la concurrencia de circunstancias específicas y calificadas ${ }^{73}$. Lo anterior se levanta sobre la creencia del beneficio que dicho contacto y cuidado le reporta al hijo, aunque obviamente lo relevante es la calidad de la relación. En Reino Unido, donde el cuidado, custodia o parentalidad está referida principalmente a los tiempos de residencia con uno u otro padre, las investigaciones sugieren que los intereses de los niños luego de la separación parental están más fuertemente relacionados con la calidad de la parentalidad que reciben que con un patrón de cuidado o cantidad de tiempo en particular ${ }^{74}$.

\section{Conclusiones}

El contenido del cuidado personal de los hijos no aparece legalmente especificado de modo directo, pero del análisis de varios elementos que consideran las transformaciones establecidas por la Ley 20.680 de 2013, los derechos del padre no cuidador y los derechos de los hijos, es posible afirmar que el cuidado personal se refiere hoy a los cuidados y atenciones diarias y habituales del hijo, supone la convivencia con este y habilita al ejerciente para tomar las decisiones corrientes y cotidianas que se refieran al hijo, al tiempo que le impone ciertos deberes.

Como función emanada de la autoridad parental, el cuidado personal no es un derecho absoluto, porque se ejerce en interés de los hijos. Es una función básica -y por lo mismo trascendente- de la relación de filiación, que se encuentra subordinada al interés y beneficio preferente del hijo, pues este es protagonista principal del derecho.

La recepción expresa del principio de corresponsabilidad parental y con ello del deber de ambos padres de participar activa, equitativa y permanentemente en la crianza y educación de los hijos, vivan juntos o separados, ha situado las funciones de crianza y educación tradicionalmente asociadas al contenido exclusivo del cuidado personal, en ambos padres como una consecuencia directa de la relación de filiación, dando lugar a una visión más equilibrada de los roles parentales, al tiempo que se respetan los derechos de los hijos a relacionarse con ambos padres y a ser guiados y educados por ellos. El cuidado personal no implica hoy para el padre cuidador facultades excluyentes o una mejor posición frente del padre no cuidador, al menos, en cuanto a las funciones de

73 Cfr. art. 226 CC.

${ }^{74}$ Maclean, 2017, p. 174-175. La misma autora explica que la parentalidad compartida (custodia compartida) es diferente de la responsabilidad parental que ambos padres conservan después de la separación (p. 165). 
crianza y educación de los hijos. Desde este punto de vista, se ha reducido el contenido del cuidado personal y se ha proporcionado una nueva mirada a la responsabilidad parental, lo que tiene particular relevancia luego de una crisis familiar y en todos los eventos en que los padres viven separados.

La reducción antedicha no implica que el cuidado aparezca restringido únicamente a una función de carácter material, referida solo a la residencia y convivencia habitual con el hijo; el renovado enfoque de la relación paterno-filial en perspectiva del bien de los hijos también ha traído como consecuencia el establecimiento expreso de varios deberes que forman parte del contenido actual del cuidado; especialmente de cooperación con el otro padre y de garantía de la estabilidad del hijo.

Esta nueva perspectiva da un vuelco al sistema anteriormente imperante basado, entre otros caracteres, en el amplio poder del padre cuidador y la preponderancia de sus intereses, para construir otro que, cimentado en el superior interés del hijo y la corresponsabilidad parental, demanda la participación de ambos padres en su crianza y educación.

\section{BIBLIOGRAFÍA}

Abeliuk, René, 2003: La filiación y sus efectos, tomo I, Santiago Editorial Jurídica de Chile.

Acuña San Martín, Marcela, 2011: Efectos Jurídicos del Divorcio, Santiago, Thomson Reuters.

Acuña San Martín, Marcela, 2013: "El principio de corresponsabilidad parental", Revista de Derecho, Universidad Católica del Norte, año 20, Nº 2.

Acuña San Martín, Marcela, 2014: Derecho de Relación Directa y regular, Santiago, Thomson Reuters.

ACuña San Martín, Marcela, 2016a: "Relaciones Jurídicas entre los padres y el (la) hijo (a). Filiación”, en Del Picó, Jorge (coord.), Derecho de Familia, pp. 419-572, Santiago, Thomson Reuters.

Acuña San Martín, Marcela, 2016b: "Ejercicio abusivo del cuidado personal que daña a los hijos”, Columna de Análisis Jurídico, El Mercurio Legal.

Acuña San Martín, Marcela, 2017: "Modificación del cuidado personal de los hijos por obstaculizar el ejercicio del derecho de relación directa y regular”, en Guzmán Brito, Alejandro (ed.), Aportaciones adicionales a nuevos horizontes en el Derecho Privado, Valparaíso, Ediciones Universitarias de Valparaíso.

Aramburu, Isabel, 2006: Estudio de derecho comparado sobre la regulación de la custodia compartida, Madrid, Themis.

Arancibia, María; Cornejo, Pablo, 2014: "El derecho de familia en Chile. Evolución y nuevos desafíos". Ius et Praxis, Año 20, No 1.

Ascencio Hernández, Alicia, 2000: El cuidado de los hijos en la familia disociada. Criterios de atribución, Universidad Adolfo Ibáñez.

Barcia Lehmann, Rodrigo, 2013: "Hacia un sistema de filiación que consagre facultades y derechos específicos para el padre no custodio”, Revista de Derecho (Valdivia), Vol. XXVI, No 2.

Bavestrello, Irma, 2003: Derecho de Menores. Santiago, LexisNexis.

Bossert, Gustavo y Zannoni, Eduardo, 2016: Manual de derecho de familia, $7^{a}$ edición, Buenos Aires, Astrea.

BRIDGEMAN, Jo, 2017: "Responsabilidad: protegiendo el bienestar y promoviendo la autonomía”, en Lathrop, Fabiola y Espejo, Nicolás (coords), Responsabilidad parental, Santiago, Thomson Reuters. 
De La Iglesia Monje, María, 2008: "Las funciones del progenitor custodio y el derecho de visitas del no custodio (I)", Revista Critica de Derecho Inmobiliario, Madrid, No 710 .

Domínguez, Carmen, 2010: “Cuidado personal de los hijos ¿deber compartido?”, Santiago, Centro de la Familia UC.

EeKelaAr, John, 2017: “Responsabilidad parental como privilegio”, en Lathrop, Fabiola y Espejo, Nicolás (coords.), Responsabilidad parental, Santiago, Thomson Reuters.

Etcheberry, Leonor, 2014: “Análisis Crítico de la ley No 20.680”. Estudios de Derecho Civil IX, Santiago, Thomson Reuters.

García Presas, Inmaculada, 2015: Guarda y Custodia de los hijos, Lisboa, Juruá.

Gete-Alonso y Calera, María y Solé, Judith, 2015: Custodia Compartida Derecho de los hijos y de los padres. Navarra, Aranzadi.

Gómez De La Torre, Maricruz, 2007: El sistema filiativo chileno, Santiago, Editorial Jurídica de Chile.

Guilarte Martín-Calero, Cristina, 2014: La concreción del interés del menor en la jurisprudencia del tribunal supremo, Valencia, Tirant lo Blanch.

Lathrop, Fabiola, 2005: Cuidado personal de los hijos, Santiago, Puntolex.

Lathrop, Fabiola, 2008: "Algunas consideraciones en torno a la custodia compartida de los hijos", Revista Chilena de Derecho Privado, $\mathrm{N}^{\circ} 10$.

Lathrop, Fabiola, 2013a: Cuidado Personal y Relación Directa y Regular. Estudio Exploratorio en los Tribunales de Familia de la Región Metropolitana, Santiago, AbeledoPerrot.

Latrhrop, Fabiola, 2013b: "Comentarios a la reforma al Código Civil en materia de efectos de la filiación”, Santiago, La Semana Jurídica, $\mathrm{N}^{\circ} 58$.

Lathrop, Fabiola, 2017: "Derecho a la vida familiar, responsabilidad parental y derechos del niño, niña y adolescente”, en Acuña San Martín, Marcela y Del Picó Rubio, Jorge (editores), Estudios de Derecho Familiar, Talca, Editorial Universidad de Talca.

LePin, Cristián, 2013: "Reformas a las relaciones paterno filiales. Análisis de la ley 20.680". Revista de Derecho, Escuela de Postgrado, No 3.

López Rivera, Gisella, 2001: Nuevo estatuto de filiación y los derechos esenciales, Santiago, Editorial Jurídica Conosur.

López SAN LuIs, Rocío, 2011: "Recientes criterios legislativos y jurisprudenciales sobre la custodia compartida”, en Rodríguez y Bravo (editoras): Experiencias jurídicas e identidades femeninas, Madrid, Dykinson, pp. 270-293.

MACLEAN, Mavis, 2017: "El cuidado de los niños después de la separación de sus padres: ¿ayuda a los niños la legislación sobre tiempo de parentalidad compartida?”, en Lathrop, Fabiola y Espejo, Nicolás (coords.), Responsabilidad parental, Santiago, Thomson Reuters.

Mazzinghi, Jorge y Mazzinghi, Esteban, 2016: Responsabilidad parental y alimentos a favor de los hijos, Buenos Aires, El Derecho.

Meza Barros, Ramón, 1979: Manual de derecho de la familia, tomo II, $2^{a}$ edición, Santiago, Editorial Jurídica de Chile.

Mizrahi, Mauricio, 2016: Responsabilidad parental, Buenos Aires, Astrea.

MorÁn GonZÁLEZ, Isabel, 2010: "El ministerio fiscal y los sistemas de guarda y custodia: especial referencia a la custodia compartida y los criterios de atribución en beneficio del menor”, en Tapia, José (dir.), Custodia Compartida y protección de menores, Madrid, CGPJ.

MuÑoz Seguel, Susana, 2011: "La mediación como instancia para la revalorización del rol paterno. Estudio exploratorio-documental”, Revista Chilena de Derecho y Ciencia Política, Santiago, Vol. 2, $\mathrm{N}^{\mathrm{o}} 2$.

Negroni, Gloria, 2014: "Corresponsabilidad parental: un cambio de enfoque radical”, Santiago, Revista de Derecho de Familia, $\mathrm{N}^{\circ} 1$. 
OTÁRola, Yasna, 2013: "La autoridad parental conjunta, independiente de quien tiene el cuidado personal de los hijos, si los padres viven separados en Chile". Santiago, Anuario IDEJ.

Quintana, María Soledad, 2014: "La titularidad del cuidado personal y el ejercicio de la relación directa y regular a la luz de la jurisprudencia actual”. Revista de Derecho, Pontificia Universidad Católica de Valparaíso XLIII.

RabadÁn SÁnchez-Lafuente, Fuensanta, 2011: Ejercicio de la patria potestad cuando los padres no conviven, Navarra, Aranzadi.

Ragel SÁnchez, Luis, 2001: La guarda y custodia de los hijos, Madrid, Derecho Privado y Constitución, $\mathrm{N}^{\circ} 15$.

Ragel SÁnChez, Luis, 2003: Nulidad, separación y divorcio en la jurisprudencia, Madrid, Reus.

Rodríguez Pinto, María Sara, 2010: El cuidado personal de niños y adolescentes en el nuevo derecho chileno de familia, Santiago, AbeledoPerrot.

Rodríguez Pinto, María Sara, 2014: "Nuevas normas sobre cuidado personal, relación directa y regular, y patria potestad en el Código Civil chileno. Reformas introducidas por la Ley 20.680 de 2013". Revista de Derecho de Familia, No 1.

Ruz, Gonzalo, 2012: Explicaciones de derecho civil, tomo V, Santiago, LegalPublishing.

Salanova, Marta, 1995: "El derecho del menor a no ser separado de sus padres", Derecho Privado y Constitución, $\mathrm{N}^{\circ} 7$.

SALlÉs, Cristina y Ger, Sandra, 2011: "Las competencias parentales en la familia contemporánea: descripción, promoción y evaluación”. Revista de intervención socioeducativa, No 49.

SAn Segundo, Teresa, 2010: "Maltrato y separación: repercusiones en los hijos", en Tapia, José (dir.), Custodia Compartida y protección de menores, Madrid, CGPJ.

Schmidt, Claudia y Veloso, Paulina, 2001: La Filiación en el nuevo derecho de familia, Santiago, LexisNexis.

Schmidt, Claudia, 2004: Instituciones de derecho de familia, Santiago, LexisNexis.

Serrano Castro, Francisco, 2010: Relaciones paterno-filiales, Madrid, El Derecho.

TAPIA, Mauricio, 2013: "Comentarios críticos a la reforma del cuidado personal de los hijos (Ley 20.680)", Revista Chilena de Derecho Privado, No 21.

Tobón Berríos, Luz, 2010: "Las relaciones paterno filiares de carácter personal en el derecho francés”, Medellín, Revista Vínculos, Vol. 1, No 1.

Turner Saelzer, Susan, 2013: "La nueva regulación legal del cuidado personal de los hijos en caso de separación de sus padres”, http://www.derecho.uach.cl/noticias/?p=3062. [Fecha consulta: 15.3 .2017$]$

VIÑAs, Dolors, 2012: "Medidas relativas a los hijos menores en caso de ruptura. Especial referencia a la guarda”, Barcelona, InDret.

Normas jurídicas citadas:

Código Civil

Convención Sobre los Derechos Del niño, adoptada con fecha 20 de noviembre de 1989.

Publicada en Chile con fecha 27 de septiembre de 1990.

LEy 20.680, publicada el 21 de junio de 2013.

Jurisprudencia citada:

Corte Suprema, sentencia de 11 de julio de 2017, rol 4827-2017

Corte Suprema, sentencia de 19 de julio de 2017, rol: 4951-2017. 
Corte Suprema, sentencia de 23 de mayo de 2017, rol 9986116.

Corte Suprema, sentencia de 4 septiembre 2014, rol 21334-2014.

Tribunal Constitucional, sentencia de 16 de junio de 2015, rol No 2699-14-INA.

CIDH, sentencia de 24 de febrero de 2012, Átala Riffo y niñas vs. Chile. 
